dr inz. Stanistaw Bocian

mgr inz. Jerzy Fraczek

mgr inz. Mieczystaw Stypka

Instytut Pojazdów Szynowych "TABOR"

\title{
Urządzenie symulujące pracę układu hamulcowego pojazdu szynowego
}

\begin{abstract}
$W$ artykule omówiono urzqdzenie stużace do symulacji $w$ określonym zakresie pracy układu hamulcowego pojazdu szynowego. Omawiane urzqdzenie jest zbudowane na bazie odpowiednio oprogramowanego sterownika programowalnego PLC. Konfiguracja urzqdzenia jest realizowana przez program omówiony $w$ [1], który $w$ tym celu zostat rozbudowany o potrzebne funkcje. Uktad pracuje $w$ ramach komunikacyjnej sieci przemystowej CANopen [2] wykorzystywanej obecnie w uktadach sterujaco - pomiarowych pojazdów szynowych.

Celem budowy tego urzadzenia jest umożliwienie testowania $w$ warunkach laboratoryjnych niektórych aspektów tworzonych układów sterujacych hamulca. Artykut powstat w wyniku realizacji Projektu Badawczego MN i SzW nr N N509 398236 „,Mikrosystemy cyfrowe do inteligentnego, rozproszonego i wspótbieżnego sterowania pojazdami szynowymi".
\end{abstract}

\section{Wprowadzenie}

Niniejszy opis dotyczy urządzenia symulującego w określonym zakresie pracę układu

hamulcowego pojazdu trakcyjnego. Urządzenie generuje dwa przebiegi prądowe w zakresie $4 . .20 \mathrm{~mA}$. Odpowiadają one przebiegom wyjściowym dwóch przetworników ciśnienia mierzących ciśnienia realizowane przez układ hamulcowy. Urządzenie symuluje układ hamulcowy wyposażony w sterownik pracujący w sieci CANopen. Oznacza to, że odbiera od układu nadrzędnego takie same zlecenia jak układ rzeczywisty (przez sieć CANopen) i na swoich wyjściach wytwarza przebiegi sygnałów odpowiadające rzeczywistym przebiegom ciśnień. Typowo są to ciśnienia: $\mathrm{w}$ przewodzie głównym $\mathrm{i}$ w cylindrze hamulcowym. Obecnie przebiegi są realizowane w sposób przybliżony czyli jako zmieniające się liniowo w czasie.

Omawiane urządzenie jest zrealizowane na bazie sterownika programowalnego PLC firmy WAGO

(p.2). Program sterownika Copn_s2 został napisany w środowisku WAGO - IO - Pro32 wersja 2.1.

\section{Konfiguracja sprzętowa sterownika}

Urządzenie zbudowano z elementów wchodzących w skład systemu modułowego WAGO - I/O -

SYSTEM 750 firmy WAGO.

Niezbędny zestaw modułów, to:

- 750-837 moduł sterownika programowalnego i wę-

zła sieci CANopen [5]

- moduł wyjść analogowych $0 . .20 \mathrm{~mA}$

$-750-552$ (2 wyjścia $0 . .20 \mathrm{~mA}$ ) lub

$-750-553$ (4 wyjścia $0.20 \mathrm{~mA}$ )

-750-600 moduł końcowy.

\section{Konfiguracja sterownika jako węzła sieci} CANopen

Omawiane urządzenie współpracuje z komputerem (lub sterownikiem) zewnętrznym za pośrednictwem sieci CANopen. W celu zapewnienia poprawnej współpracy elementy CANopen muszą być odpowiednio skonfigurowane. Do wykonania tego zadania można użyć dowolnego programu konfiguracyjnego CANopen. Szczególne ułatwienia zawiera program Copn_m [1].

Konfiguracja dotyczy głównie obiektów Pdo służących do wymiany informacji. Konfiguracja polega na wykonaniu odpowiednich zapisów w słowniku obiektów węzła CANopen za pomocą serwisu Sdo $[1,2]$.

Oprogramowanie systemowe CANopen sterownika WAGO zawiera standardowy układ obiektów RPdo1..4 i TPdo1..4 [1]. Konfiguracja dodatkowych obiektów Pdo obejmuje przydzielenie tym obiektom identyfikatorów COB - ID. Identyfikatory te są przydzielane zgodnie z zasadą opisaną w [3], p.4.2.

\section{Oprogramowanie sterownika}

Sterownik ma załadowany program WG_Copn_s2, który realizuje dwie funkcje. Funkcją główną jest symulacja sygnałów wyjściowych dwóch przetworników ciśnienia pracujących w układzie hamowania. Funkcja pomocnicza jest edycja i modyfikacja tablic zawierających dane dla realizacji funkcji głównej.

\subsection{Symulacja przetworników ciśnienia}

Program steruje dwoma wyjściami analogowymi, prądowymi $4 . .20 \mathrm{~mA}$. Sygnały wyjściowe symuluja sygnały wyjściowe dwóch przetworników ciśnienia. 
Symulowane ciśnienia oznaczane są pMG i pMC (ciśnienie w przewodzie głównym i cylindrze hamulcowym). Przyjmuje się, że charakterystyka symulowanych czujników jest liniowa i przechodzi przez punkty: $0 \mathrm{kPa}-4 \mathrm{~mA}, 1000 \mathrm{kPa}-20 \mathrm{~mA}$.

Program steruje zmianami sygnałów wyjściowych zgodnie ze zleceniami odbieranymi przez sieć CANopen. Zlecenia informują o wymaganym typie badania oraz o położeniu nastawnika hamowania. Dla każdego typu badania jest określona na stałe liczba położeń nastawnika. Dla każdego położenia nastawnika są określone cztery wielkości:

- wartość ciśnienia przy zwiększaniu stopnia hamowania $[\mathrm{kPa}]$

- wartość ciśnienia przy zmniejszaniu stopnia hamowania $[\mathrm{kPa}]$

- tempo zmiany ciśnienia $[\mathrm{kPa} / \mathrm{s}]$ lub czas dojścia do ciśnienia [s] przy zwiększaniu stopnia hamowania

- tempo zmiany ciśnienia $[\mathrm{kPa} / \mathrm{s}]$ lub czas dojścia do ciśnienia [s] przy zmniejszaniu stopnia hamowania.

Obecnie standardowy zestaw danych jest przygotowany pod kątem badań układu hamulcowego i obejmuje realizację pięciu typów badań:

- HZ - hamulec zespolony

- HD - hamulec dodatkowy

- HN - hamowanie nagke

- PS - próba szczelności

- WC - wyrównywanie ciśnień

Program steruje zmianami sygnałów wyjściowych zgodnie ze zleceniami odbieranymi przez sieć CANopen. Zlecenia są przesyłane do sterownika za pomocą dwóch obiektów: Pdo5 i Pdo6.

$\mathrm{Sa}$ to zlecenia analogiczne do zleceń wysyłanych przez rzeczywisty układ sterujący hamulcem do sterownika wykonawczego hamulca.

\subsection{Możliwości modyfikacji bazy danych sterownika}

W programie są zapisane tablice zawierające standardowe dane (ciśnienia i tempa zmiany lub

czasy) dla wszystkich typów danych. Podczas pracy programu dane te mogą być edytowane i modyfikowane. Po zresetowaniu programu tablice przyjmują na powrót wartości standardowe.

Powyższa edycja i modyfikacja bazy danych sterownika jest wykonywana za pomocą programu [1] pracującego na komputerze PC i również włączonego do sieci CANopen. W stosunku do wersji opisanej w [1] program został rozszerzony o funkcję umożliwiająca wygodną realizację powyższego zadania. Rys. 1 przedstawia okno programu, które pokazuje prawidłowe wartości ciśnienia. Rys. 2 przedstawia okno programu, które pokazuje nieprawidłowe wartości ciśnienia. Dodatkowo z poziomu tego programu (rys. 1 i 2), na karcie 'Sterowanie ręczne' można ustawiać dowolne stany wyjść symulatora i zlecać realizację przebiegów ciśnień.

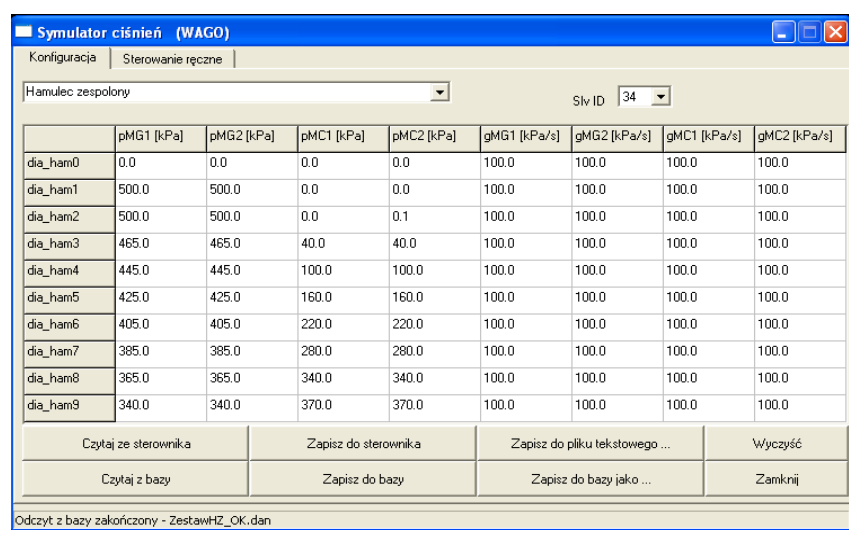

Rys. 1. Zestaw danych dla próby z prawidłowymi wartościami ciśnień MG i MC.

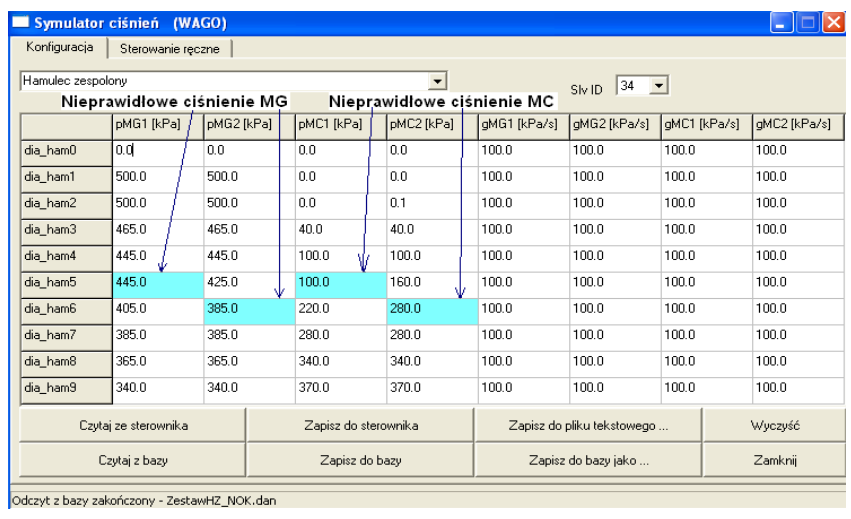

Rys. 2. Zestaw danych dla próby z nieprawidłowymi wartościami ciśnień MG i MC.

\section{Przykład współpracy symulatora z rzeczywistym ukladem sterownia hamulcem}

$\mathrm{Na}$ rysunku 3 przedstawiony jest schemat blokowy współpracy symulatora ciśnień ze sterownikiem pneumatyki. W układzie tym można testować wybrane fragmenty algorytmu związane $\mathrm{z}$ próbami hamulcowymi. Dla przeprowadzenia wybranych prób układu pneumatycznego $\mathrm{w}$ założonym zakresie zaangażowane są następujące elementy układu sterowania:

- sterownik główny lokomotywy (MASTER),

- sterownik pneumatyki (SLAVE1),

- symulator ciśnień tablicy pneumatycznej (SLAVE2),

- symulator manipulatorów pulpitowych i paneli operatorskich,

- komputer serwisowy.

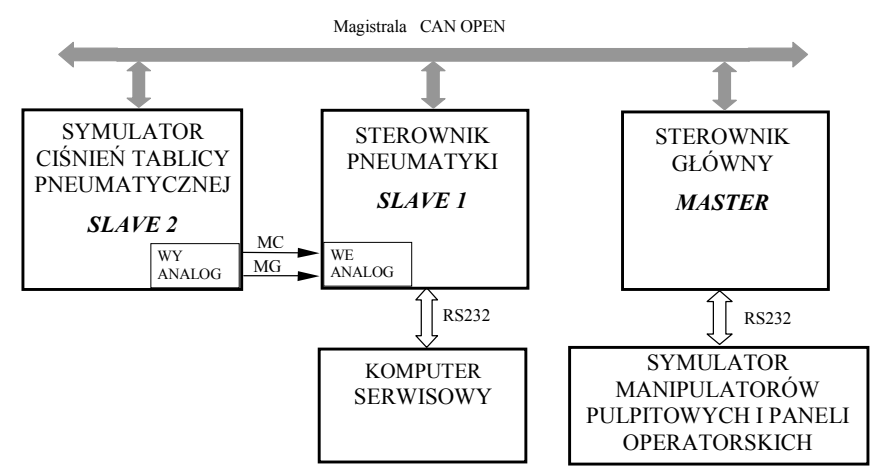

Rys. 3. Schemat blokowy współpracy symulatora ze sterownikiem pneumatyki 
Na rysunku 4 przedstawiona jest realizacja sprzętowa układu przedstawionego na rysunku 3.

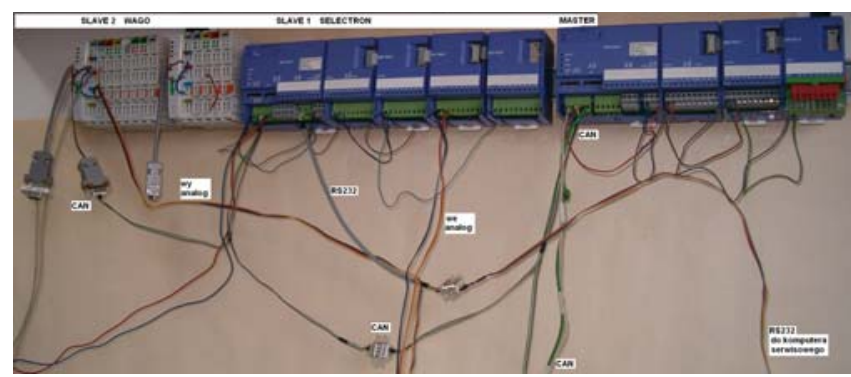

Rys 4. Schemat montażowy symulatora układu pneumatycznego lokomotywy

W układzie na rysunku 4 zastosowano następujące sterowniki:

1. Master - sterownik mikroprocesorowy CPU 723-T

+ moduł 8 wyjść cyfrowych DOT701 + moduł 8 wejść cyfrowych DIT 701

2. Slave $1-$ sterownik CPU $723-T+$ moduł 8 wyjść cyfrowych DOT701 + moduł 8 wejść analogowych AIT $701+$ moduł 8 wejść cyfrowych DIT 701

3. Slave $2-$ sterownik WAGO + moduł wejść cyfrowych + moduł wyjść cyfrowych + moduł 2 wyjść analogowych.

$\mathrm{Na}$ rysunku 5 przedstawiono widok aplikacji Symulator Manipulatorów i Pulpitu za pomocą której możemy generować sygnały po RS232 odpowiadające wybranym stanom $\mathrm{z}$ manipulatorów lub $\mathrm{z}$ panelu. Umożliwia to wstępne testowanie algorytmów sterowników mikroprocesorowych bez rozbudowania układu. Właściwa weryfikacja algorytmów powinna być realizowana w układzie jak najbardziej zbliżonym do układu docelowego.

Przy pomocy pól poniżej napisu „Generowanie stanu wejść cyfrowych" można wstawić stan 40 sygnałów binarnych odpowiadających potrzebnym dla danej próby sygnałom cyfrowym $\mathrm{z}$ manipulatorów lub $\mathrm{z}$ panelu. Przy pomocy pól poniżej napisu „Generowanie stanu wejść analogowych” można zadać wartości 8 sygnałów analogowych (ciśnień). W tabeli „ODEBRANE DANE” można obserwować na bieżąco wszystkie zmienne cyfrowe (wejściowe i wyjściowe) oraz analogowe $\mathrm{z}$ testowanego sterownika mikroprocesorowego, które równolegle zapisywane są na dysku komputera.

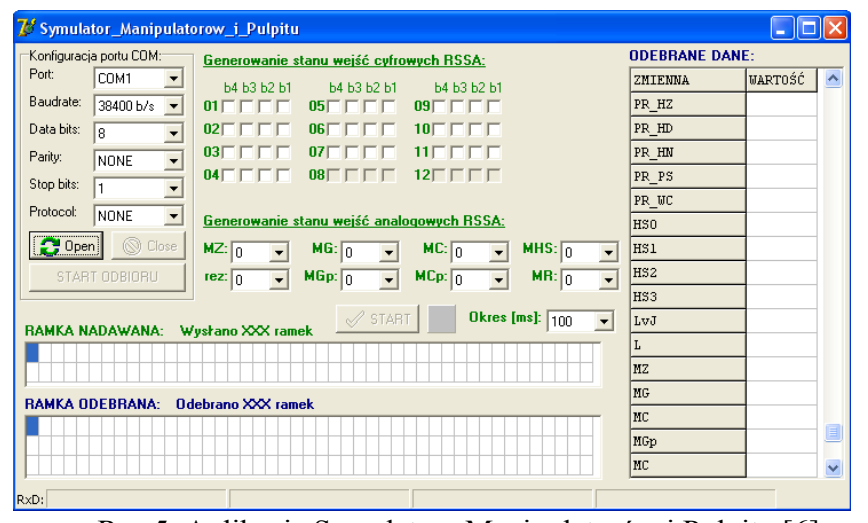

Rys 5. Aplikacja Symulatora Manipulatorów i Pulpitu [6]
Za pomocą powyższej aplikacji możemy przeprowadzić różne testy w zależności od potrzeb. Możemy programowo wybrać próbę ręczną i próbę automatyczną. Próba ręczna (PR_HZ) wymaga zmiany stopni hamowania hamulca zespolonego lub hamulca dodatkowego przez operatora a zmiany ciśnień realizowane są automatycznie według założonego programu przez SYMULATOR CIŚNIEŃ TABLICY PNEUMATYCZNEJ. Przy próbie automatycznej (PR_HZ) zmiany stopni hamowania hamulca zespolonego realizowane są automatycznie, a zmiany ciśnień realizowane są również automatycznie jak powyżej.

Opisano przebieg próby hamulca zespolonego przy realizowaniu zestawu 1

(rys. 1) z prawidłowymi wartościami ciśnień w cylindrach hamulcowych MC i ciśnienia w przewodzie głównym MG oraz przy realizowaniu zestawu 2 (rys 2) z nieprawidłowymi wartościami ciśnień MC i MG. Sterownik główny otrzymuje sygnały $\mathrm{z}$ symulatora manipulatorów pulpitowych i panelu operatorskiego dotyczące rodzaju próby i sposobu jej przeprowadzenia. Sygnały te przesyłane są do sterownika pneumatyki, który realizuje odpowiedni algorytm wybranej próby i do symulatora ciśnień, który generuje przebiegi ciśnień według wywołanego scenariusza. Przebieg całej próby jest rejestrowany przez komputer serwisowy na dysku. Po zakończeniu próby zapisany plik umożliwia dokładną analizę próby i wyeliminowanie ewentualnych błędów algorytmu lub programu.

Dla uproszczenia algorytmu przyjęto, że Próba PR_HZ składa się z 16 kroków. Przed końcem danego kroku (pojawia się sygnał FOCENA - Flaga Oceny) realizowana jest ocena częściowa próby (ocena danego stopnia) a po dojściu do ostatniego 16 kroku realizowana jest ocena końcowa. Ocena końcowa próby widoczna jest do momentu zakończenia próby czyli zmiany sygnału PR_HZ na 0 . W tabeli 1 przedstawiono program działania hamulca zespolonego według którego realizowano próbę PR_HZ.

Próba stopniowania hamulca zespolonego polega na zmianie kolejnych stopni hamowania od pozycji wyluzowanego hamulca (L - dla dia_ham1) do maksymalnego stopnia hamowania (tutaj przyjęto 7 stopni hamowania) i następnie z powrotem do pozycji LvJ (dia_ham2) „pozycja jazdy”. Daje to 16 kroków a $\mathrm{w}$ każdym $\mathrm{z}$ nich następuje zmiana stopnia hamowania oraz zmiana ciśnień. W każdym kroku realizowana jest przez sterownik pneumatyki ocena zarówno dla ciśnienia MC jak i dla ciśnienia MG. Nieprawidłowy stan jest zapamiętywany i po przejściu całej procedury generowana jest ocena negatywna dla danej próby. Ocena pozytywna jest wtedy gdy nie ma w kolejnych krokach żadnej oceny negatywnej. Na rysunku 6 przedstawiony jest przebieg sygnałów związanych $\mathrm{z}$ daną próbą. Na rysunku 7 przedstawiony jest przebieg próby z prawidłowymi ciśnieniami a na rysunku 8 przebieg z nieprawidłowymi ciśnieniami. 
Tabela 1. Przykładowy program dzialania manipulatora hamulca zespolonego

\begin{tabular}{|c|c|c|c|c|c|c|c|c|c|c|}
\hline \multirow{2}{*}{\multicolumn{2}{|c|}{$\begin{array}{l}\text { Funkcja hamulca } \\
\text { zespolonego }\end{array}$}} & \multicolumn{7}{|c|}{ Stan zaworów elektropneumatycznych } & \multicolumn{2}{|c|}{$\begin{array}{l}\text { Sygnały dla } \\
\text { SLAVE2 }\end{array}$} \\
\hline & & $\stackrel{\ominus}{\mathscr{I}}$ & $\overline{\mathscr{I}}$ & $\stackrel{N}{\mathscr{I}}$ & $\stackrel{\mathscr{n}}{\mathscr{I}}$ & 3 & $\dashv$ & 具 & $\begin{array}{l}\text { rosnące } \\
\text { st.Ham }\end{array}$ & $\begin{array}{l}\text { malejacce } \\
\text { st.Ham }\end{array}$ \\
\hline \multicolumn{2}{|l|}{ Luzowanie } & 0 & 0 & 0 & 0 & 1 & 1 & 1 & dia_ham & \\
\hline \multicolumn{2}{|c|}{ Jazda (stan gotowości) } & 0 & 0 & 0 & 0 & 0 & 1 & 1 & ${ }_{2}^{\text {dia_ham }}$ & dia_ham \\
\hline \multirow{7}{*}{$\begin{array}{l}\text { Hamowanie } \\
\text { stopniowe }\end{array}$} & I stopień & 1 & 1 & 0 & 0 & 0 & 0 & 1 & $\begin{array}{l}\text { dia_ham } \\
3\end{array}$ & $\begin{array}{l}\text { dia_ham } \\
3\end{array}$ \\
\hline & II stopień & 1 & 0 & 1 & 0 & 0 & 0 & 1 & dia_ham & dia_ham \\
\hline & III stopień & 1 & 1 & 1 & 0 & 0 & 0 & 1 & $\begin{array}{l}\text { dia_ham } \\
5\end{array}$ & dia_ham \\
\hline & IV stopień & 1 & 0 & 0 & 1 & 0 & 0 & 1 & $\begin{array}{l}\text { dia_ham } \\
6\end{array}$ & $\begin{array}{l}\text { dia_ham } \\
6\end{array}$ \\
\hline & V stopień & 1 & 1 & 0 & 1 & 0 & 0 & 1 & $\begin{array}{l}\text { dia_ham } \\
7\end{array}$ & dia_ham \\
\hline & VI stopień & 1 & 0 & 1 & 1 & 0 & 0 & 1 & $\begin{array}{l}\text { dia_ham } \\
8\end{array}$ & $\begin{array}{l}\text { dia_ham } \\
8\end{array}$ \\
\hline & VII stopień & 1 & 1 & 1 & 1 & 0 & 0 & 1 & $\begin{array}{l}\text { dia_ham } \\
9\end{array}$ & \\
\hline \multicolumn{2}{|c|}{ Hamowanie nagłe } & \multicolumn{6}{|c|}{ Stan dowolny } & 0 & & \\
\hline \multicolumn{9}{|c|}{$\begin{array}{l}1 \text { - zawór elektropneumatyczny wzbudzony } \\
0-\text { zawór elektropneumatyczny nie wzbudzony }\end{array}$} & & \\
\hline
\end{tabular}

Sygnały cyfrowe od zadajnika do sterownika pneumatyki biorące udział w próbie HZ HSO, HS1, HS2, HS3, LvJ,L,HN

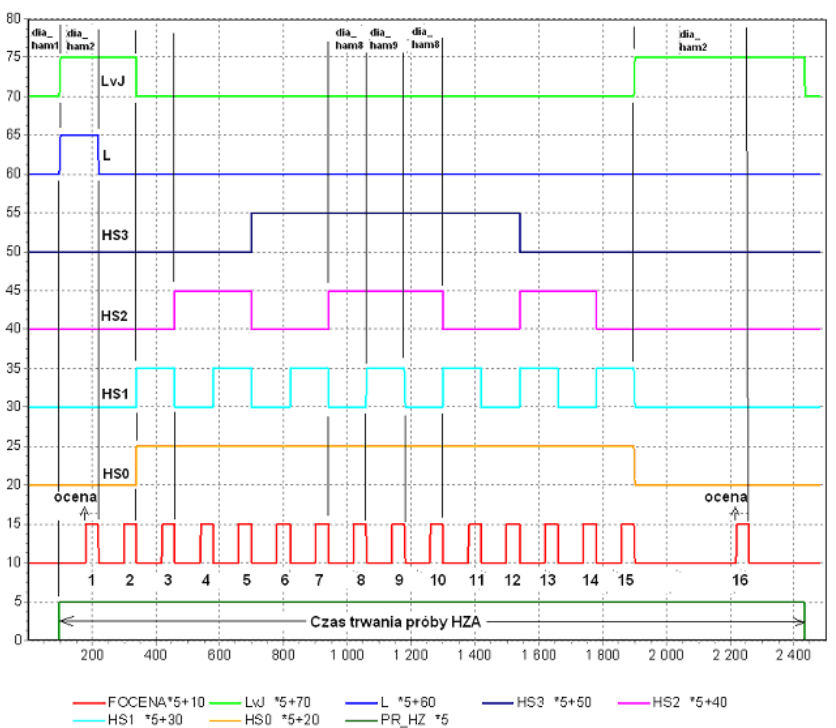

Rys 6. Przebieg sygnałów podczas próby hamulca zespolonego PR HZ
FOCENA - sygnał dla oceny danego stopnia hamowania, ocena realizowana jest po pojawieniu się zbocza dodatniego sygnału, korelacja pomiędzy sygnałem FOCENA o stopniami hamowania przedstawiona jest na rysunku 6 .

LvJ, L, HS0, HS1, HS2, HS3 - sygnały generowane automatycznie według tabeli 1

Dla lepszej widoczności przebiegi cyfrowe FOCENA, LvJ, L, HS0, HS1, HS2, HS3 i PR HZ są przesunięte o 10 jednostek i pomnożone przez 5. Skala osi x wyrażona jest $\mathrm{w}$ cyklach sterownika mikroprocesorowego przy czym 1 cykl $=100 \mathrm{~ms}$. Przedstawiony przebieg trwający 2500 cykli oznacza czas próby $250 \mathrm{~s}$. Użyte skróty oznaczają:

PR_HZ - wybór próby hamulca zespolonego

OMG_N - ocena ciśnienia MG dla danego stopnia hamowania, w przypadku oceny negatywnej sygnał OMG $\mathrm{N}=1$

OMC_N - ocena ciśnienia MC dla danego stopnia hamowania, w przypadku oceny negatywnej sygnał $\mathrm{OMC} \mathrm{N}=1$

OK_P - ocena końcowa próby, gdy jest pozytywna sygnał $\mathrm{OK} . \mathrm{P}=1$

OK_N - ocena końcowa próby, gdy jest negatywna sygnał OK._N $=1$

Na rysunku 7 przedstawiony jest przebieg próby hamulca zespolonego gdy wartości ciśnień dla odpowiednich stopni hamowania są prawidłowe i ocena końcowa próby jest pozytywna. 


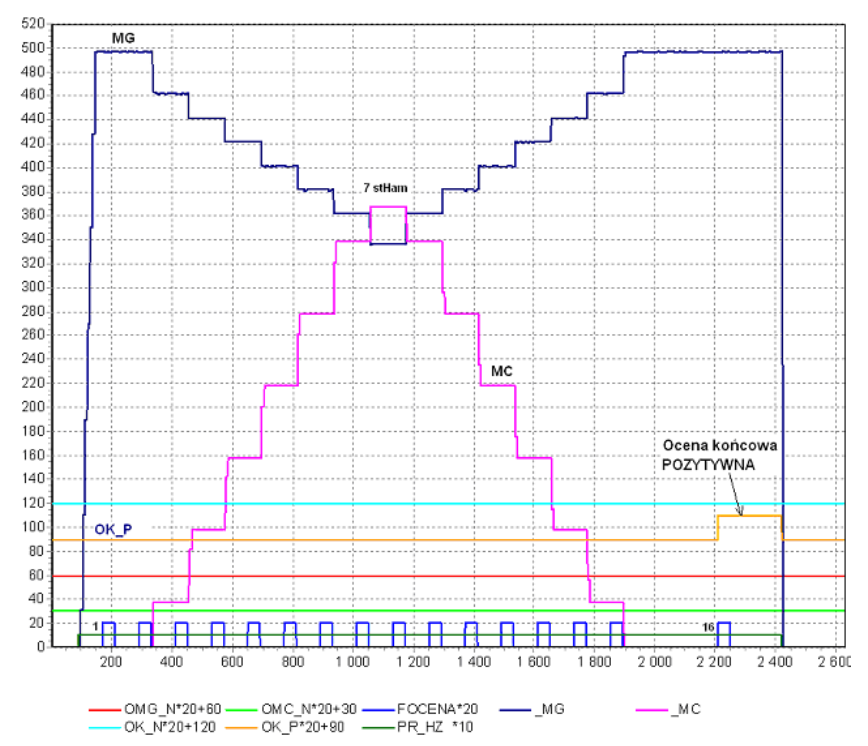

Rys 7. Przebieg próby hamulca zespolonego przy prawidłowej wartości ciśnień MC i MG

$\mathrm{Na}$ rysunku 7 wszystkie wartości dla kolejnych przejść są prawidłowe i oceny kolejnych kroków OMC_N, OMG_N są równe 0. W przypadku gdy wszystkie oceny pośrednie są pozytywne to końcowa ocena też jest pozytywna.

Na rysunku 8 wartości 2 stopni hamowania nie mają prawidłowej wartości ciśnienia $\mathrm{MG}$ i $\mathrm{MC}$ dla tych przypadków ocena pośrednia OMG_N i OMC_N ma wartość 1 . W przypadku gdy tylko jedna ocena pośrednia ma wartość 1 to końcowa ocena jest negatywna

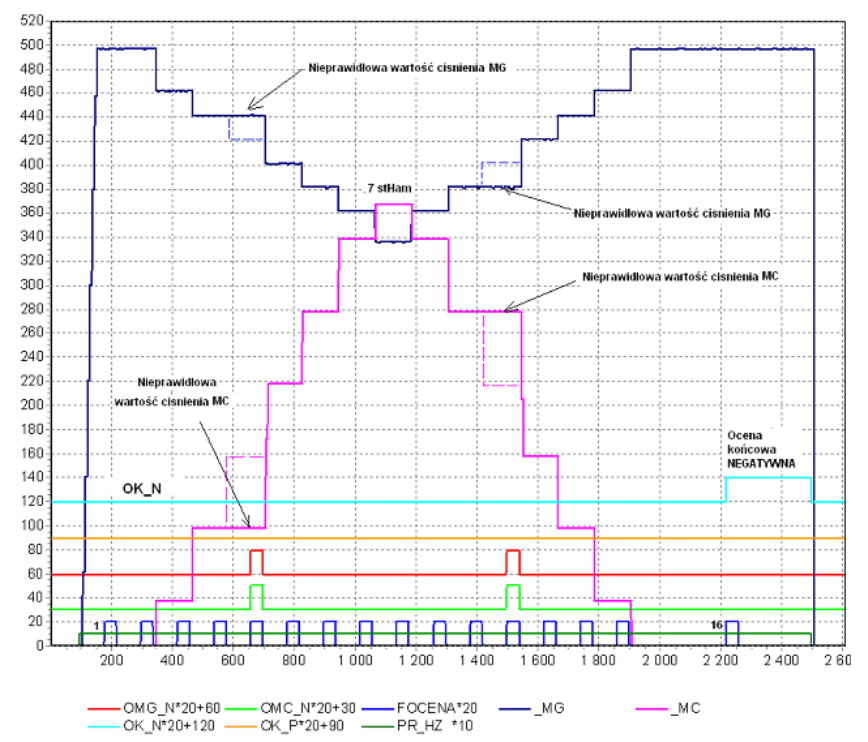

Rys 8. Przebieg próby hamulca zespolonego przy nieprawidłowej wartości ciśnień MC i MG

\section{Podsumowanie}

W opracowaniu przedstawiono wykorzystanie SYMULATORA CIŚNIEŃ TABLICY PNEUMATYCZNEJ do testowania algorytmu prób hamulca zespolonego. Po dodaniu kolejnych wyjść analogowych do układu symulatora można włączyć do testowania dodatkowe sygnały ciśnień. Przez odpowiedni dobór testów zapisanych do symulatora można wszechstronnie sprawdzić działanie algorytmu diagnostyki tablicy pneumatycznej. Mimo, że końcowym sprawdzianem działania algorytmu są jego testy na obiekcie rzeczywistym, to jednak zastosowanie symulatora umożliwi wyeliminowanie błędów na etapie wcześniejszym.

\section{Literatura}

[1] Bocian S., Fraczek J.: Program do badań uktadu sterujaco - pomiarowego, pracujacego w sieci CANopen, przeznaczonego do pojazdu szynowego, Poznań, IPS „,TABOR”, Pojazdy Szynowe nr4/2008.

[2] Fraczek J.: Koncepcja uktadu do badania algorytmów sterujacych w pojazdach szynowych. Opisu układu sieciowego CANopen. Opracowanie OR-9200. Archiwum, IPS ,,TABOR”. Poznań maj 2009.

[3] Fraczek J.: Koncepcja układu do badania algorytmów sterujacych $w$ pojazdach szynowych $w$ oparciu o sieć CANopen. Program testowy algorytmów sterujacych. Opracowanie OR-9280. Archiwum, IPS „TABOR". Poznań styczeń 2010.

[4] Stypka M.: Urzadzenie symulujqce prace uktadu hamulcowego pojazdu szynowego. Opracowanie OR9280. Archiwum, IPS „TABOR”. Poznań marzec 2010.

[5] Modular I/O system. CANopen 750-837. Manual. m083700e.pdf. WAGO Kontakttechnik GmbH, Hansastraße 27, D-32423 Minden, Version 1.0.0., 2005, www.wago.com

[6] Haba M.: Opracowanie wtasne. IPS „TABOR”. Poznań. 